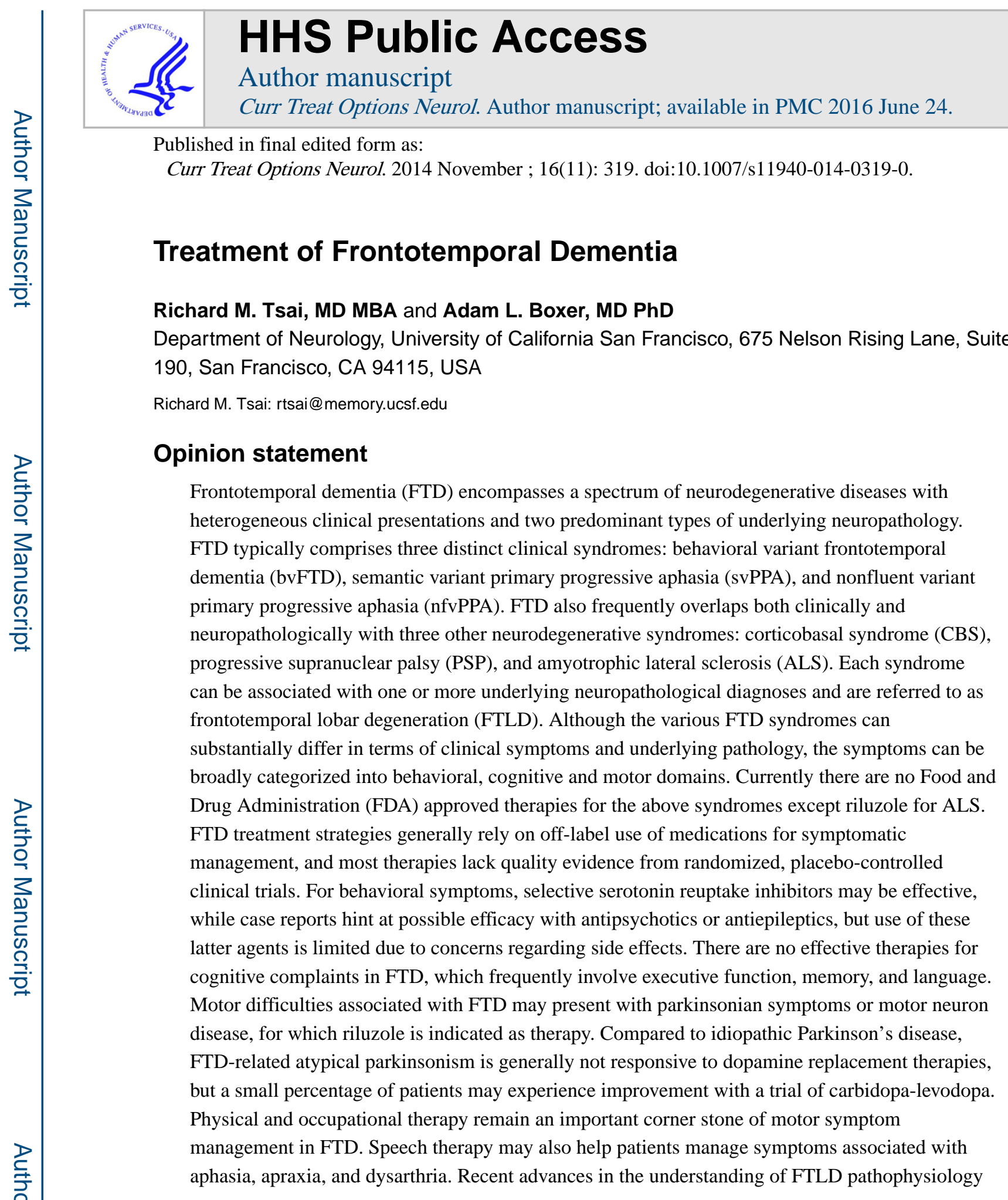

Published in final edited form as:

Curr Treat Options Neurol. 2014 November ; 16(11): 319. doi:10.1007/s11940-014-0319-0.

\title{
Treatment of Frontotemporal Dementia
}

\author{
Richard M. Tsai, MD MBA and Adam L. Boxer, MD PhD \\ Department of Neurology, University of California San Francisco, 675 Nelson Rising Lane, Suite \\ Richard M. Tsai: rtsai@memory.ucsf.edu
}

\section{Opinion statement}

Frontotemporal dementia (FTD) encompasses a spectrum of neurodegenerative diseases with heterogeneous clinical presentations and two predominant types of underlying neuropathology. FTD typically comprises three distinct clinical syndromes: behavioral variant frontotempora dementia (bvFTD), semantic variant primary progressive aphasia (svPPA), and nonfluent variant primary progressive aphasia (nfvPPA). FTD also frequently overlaps both clinically and neuropathologically with three other neurodegenerative syndromes: corticobasal syndrome (CBS), progressive supranuclear palsy (PSP), and amyotrophic lateral sclerosis (ALS). Each syndrome can be associated with one or more underlying neuropathological diagnoses and are referred to as (FTLD). Although the various FTD syndromes can substantially differ in terms of clinical symptoms and underlying pathology, the symptoms can be broadly categorized into behavioral, cognitive and motor domains. Currently there are no Food and Drug Administration (FDA) approved therapies for the above syndromes except riluzole for ALS. FTD treatment strategies generally rely on off-label use of medications for symptomatic management, and most therapies lack quality evidence from randomized, placebo-controlled clinical trials. For behavioral symptoms, selective serotonin reuptake inhibitors may be effective, while case reports hint at possible efficacy with antipsychotics or antiepileptics, but use of these latter agents is limited due to concerns regarding side effects. There are no effective therapies for cognitive complaints in FTD, which frequently involve executive function, memory, and language. Motor difficulties associated with FTD may present with parkinsonian symptoms or motor neuron disease, for which riluzole is indicated as therapy. Compared to idiopathic Parkinson's disease, FTD-related atypical parkinsonism is generally not responsive to dopamine replacement therapies, but a small percentage of patients may experience improvement with a trial of carbidopa-levodopa. Physical and occupational therapy remain an important corner stone of motor symptom aphasia, apraxia, and dysarthria. Recent advances in the understanding of FTLD pathophysiology

Correspondence to: Richard M. Tsai, rtsai@memory . ucsf .edu.

This article is part of the Topical Collection on Dementia

Compliance with Ethics Guidelines

Human and Animal Rights and Informed Consent

This article does not contain any studies with human or animal subjects performed by any of the authors.

Conflict of Interest

Richard M. Tsai declares no conflict of interest. 
and genetics have led to development of potentially disease-modifying therapies as well as symptomatic therapies aimed at ameliorating social and behavioral deficits.

\section{Keywords}

Frontotemporal dementia; Primary progressive aphasia; Progressive supranuclear palsy;

Corticobasal syndrome; Memantine; Acetylcholinesterase inhibitor; Clinical trials; Therapeutics

\section{Introduction}

Frontotemporal degeneration (FTD) is a common form of dementia, especially in individuals less than 65 years of age at time of diagnosis. FTD typically comprises three distinct clinical syndromes: behavioral variant frontotemporal degeneration (bvFTD), and two primary progressive aphasias (PPA): semantic variant primary progressive aphasia (svPPA) and a nonfluent variant primary progressive aphasia (nfvPPA). There are also three other neurodegenerative syndromes that frequently overlap both clinically and neuropathologically with FTD: corticobasal syndrome (CBS), progressive supranuclear palsy (PSP) and amyotrophic lateral sclerosis (ALS) [1••].

Diagnostic criteria for these syndromes have been proposed before and seminal features of each syndrome include social dysfunction, executive and behavioral changes for bvFTD [2], early semantic knowledge loss for svPPA, and motor speech deficits for nfvPPA [3]. New diagnostic criteria with multiple subtypes for CBS were recently proposed [4]. PSP is defined by early falls, ophthalmoplegia although subtypes exist [5, 6], while ALS is a motor neuron disease with increasingly recognized cognitive dysfunction [7,8]. Each syndrome can be associated with one or more underlying neuropathological diagnoses that are referred together under the umbrella term frontotemporal lobar degeneration (FTLD). The most common underlying neuropathologies in FTLD involve deposition of tau protein (FTLD-tau) or TAR DNA binding protein $43 \mathrm{kDa}$ (TDP-43; FTLD-TDP) [9].

Thus, it is clear that FTD is a diverse neurodegenerative syndrome with a heterogeneous clinical presentation. Although there are no United States Food and Drug Administration (FDA) approved therapies for FTD (except riluzole for ALS), for symptomatic management it may be helpful to group FTD symptoms into cognitive, behavioral, and motor domains. Currently used treatments are mostly off-label medications for symptomatic management and have minimal evidence from randomized, placebo-controlled trials to support their use. These therapies rely on modulation of neurotransmitter levels and do not target the underlying pathophysiology of FTD. Three factors have historically contributed to the difficulty of conducting adequately powered, placebo-controlled trials that provide the highest level of evidence. They are the limited number of cases of FTD (it is a rare disease), the heterogeneous presentations of FTD and the diverse underlying pathology for the range of FTD syndromes. 


\section{Treatment}

\section{Diet and lifestyle}

- $\quad$ Regular driving assessment should be conducted. Poor judgment, gaze abnormalities, executive dysfunction, and motor difficulties may all affect safe driving.

- $\quad$ Although a variety of epidemiologic studies suggest routine exercise and remaining cognitively active are associated with reduced risk of dementia [10], no specific life style interventions have been studied for FTD and its related disorders.

- $\quad$ No specific dietary recommendations exist for FTD and its related disorders. Mitochondrial dysfunction has been theorized to play a role in neurodegenerative pathogenesis, and has been specifically studied in PSP. A phase II/III randomized, placebo-controlled clinical trial in PSP patients using coenzyme Q10 was recently completed, and failed to demonstrate efficacy [11].

- Dysphagia to gorging on large amounts of food without swallowing or true motor dysphagia is common in FTD, and more advanced patients should be supervised while eating.

\section{Pharmacologic treatment of cognitive symptoms \\ Cholinesterase inhibitors}

- $\quad$ The three most commonly used acetylcholinesterase inhibitors, donepezil, rivastigmine, and galantamine, have been studied in FTD and related disorders. Although none were adequately powered, and only one study was placebo controlled, results have so far been disappointing across the board.

- $\quad$ For rivastigmine, a 12-month open-label study with 20 patients showed some improvements in behavioral, depressive symptoms via the Neuropsychiatric Index (NPI) score, but did not prevent cognitive deterioration as measured by the Mini-Mental State Examination (MMSE) [Class III] [12].

- $\quad$ Galantamine was investigated in 36 bvFTD and primary progressive aphasia (PPA) patients with unspecified subtype. All patients were treated in an openlabel fashion with galantamine for 18 weeks followed by a randomized, double-blind, placebo-controlled withdrawal period for 8 weeks. No significant differences were found in the bvFTD group after multiple comparison correction, while language function remained stable in some of the treated PPA group compared to placebo. It is possible that this group had the logopenic form of PPA caused by underlying Alzheimer's pathology [Class III] [13].

- In a case series of donepezil in 24 FTD patients over 6 months, four patients in the treatment arm had worsening behavior, and overall, the donepezil-treated group had greater worsening on the FTD inventory. Discontinuation of donepezil led to an abatement of behavioral symptoms [Class II] [14]. This 
finding was replicated recently in Japan in a discontinuation trial of donepezil in FTD patients [15].

- $\quad$ For the FTD related disorder PSP, physostigmine was studied in eight patients and revealed inconsistent, marginal improvements in memory [16]. Subsequently, in a small case series of six PSP patients, donepezil demonstrated no efficacy, while a randomized, placebo-controlled, doubleblind crossover trial in 21 patients found improvements in memory, but worsened motor function and activities of daily living (ADL) [Class IV] [17] [Class II] [18]. Finally, a five-patient series with rivastigmine reproduced positive effects on memory, but decreased motor function as measured by the Unified Parkinson's Disease Rating Scale (UPDRS) [Class IV] [19].

- $\quad$ Currently, the evidence suggests cholinesterase inhibitors are not effective treatments in FTD or PSP patients and may exacerbate behavioral or motor symptoms, respectively.

\begin{tabular}{|c|c|}
\hline Standard dosage & $\begin{array}{l}5 \mathrm{mg} \text { to } 10 \mathrm{mg} \text { a day, } 23 \mathrm{mg} \text { daily dose available, but patients may not tolerate } \\
\text { side effects }\end{array}$ \\
\hline Contraindications & $\begin{array}{l}\text { caution in patients with bradycardia, cardiac conduction disorder, severe ob- } \\
\text { structive pulmonary disease, peptic ulcer disease; caution when used with beta- } \\
\text { blockers }\end{array}$ \\
\hline Main drug interactions & $\begin{array}{l}\text { beta-blockers, antagonistic effects with anticholinergics, metabolized by } \\
\text { CYP450 3A4 }\end{array}$ \\
\hline Main side effects & nausea, diarrhea, insomnia, fatigue, vomit, cramps, vivid dreams, bradycardia \\
\hline Cost & inexpensive unless $23 \mathrm{mg}$ dose used \\
\hline Standard dosage & $\begin{array}{l}4 \mathrm{mg} \text { twice daily to } 12 \mathrm{mg} \text { twice daily; extended-release } 8 \mathrm{mg} \text { daily to } 24 \mathrm{mg} \\
\text { daily }\end{array}$ \\
\hline Contraindications & $\begin{array}{l}\text { caution in patients with bradycardia, cardiac conduction disorder, severe ob- } \\
\text { structive pulmonary disease, peptic ulcer disease; caution when used with beta- } \\
\text { blockers }\end{array}$ \\
\hline Main drug interactions & $\begin{array}{l}\text { beta-blockers, antagonistic effects with anticholinergics, CYP2D6 or CYP3A4 } \\
\text { inhibitors may increase serum levels of galantamine }\end{array}$ \\
\hline Main side effects & nausea, diarrhea, insomnia, fatigue, vomit, cramps, vivid dreams, bradycardia \\
\hline Cost & inexpensive \\
\hline Standard dosage & $\begin{array}{l}\text { starting at } 1.5 \mathrm{mg} \text { twice a day, titrate to } 6 \mathrm{mg} \text { twice a day. Transdermal patch } \\
\text { starts with } 4.6 \mathrm{mg} \text { per } 24 \mathrm{~h} \text {, increased to } 13.3 \mathrm{mg} \text { per } 24 \mathrm{~h} \text { after } 4 \text { weeks. }\end{array}$ \\
\hline Contraindications & $\begin{array}{l}\text { caution in patients with bradycardia, cardiac conduction disorder, severe ob- } \\
\text { structive pulmonary disease, peptic ulcer disease; caution when used with beta- } \\
\text { blockers }\end{array}$ \\
\hline Main drug interactions & beta-blockers, antagonistic effects with anticholinergics \\
\hline Main side effects & nausea, diarrhea, insomnia, fatigue, vomit, cramps, vivid dreams, bradycardia \\
\hline Cost & inexpensive, transdermal system may be slightly more expensive \\
\hline
\end{tabular}

\section{N-methyl-D-aspartic acid (NMDA) receptor antagonists}

- Memantine is a NMDA receptor antagonist indicated for the treatment of Alzheimer's disease (AD). Its possible role in excitotoxicity via NMDA receptor over-activation was thought to be a viable pathway to prevent cell death. 
- Initially, a small, open-label study demonstrated no effects of memantine in bvFTD [20], while another small case series and a phase 4 open-label memantine study suggested improvements in behavioral symptoms as measured by the NPI $[21,22]$. The efficacy of memantine was tested in two rigorous randomized, placebo-controlled clinical trials [Class II] [23••] [Class I] [24••]. Although neither enrolled the originally planned number of patients, both failed to demonstrate significant benefits on the NPI or clinical global impression of change. In addition, memantine treatment was associated with worse performance on a number of cognitive tests [24••].

- $\quad$ These studies provide fairly strong evidence that memantine is not an effective treatment for FTD and illustrates the limitations of extrapolating efficacy of drugs for FTD based on other neurodegenerative disease, despite strong scientific rationale.

\begin{aligned} & \hline Standard dosage $5 \mathrm{mg}$ daily starting dose, titrate to $10 \mathrm{mg}$ twice a day \\ & Contraindications use with caution in patients with severe hepatic or renal impairment \\ & Main drug interactions no major drug interactions \\ & Main side effects generally well tolerated, rare insomnia, confusion, dizziness, agitation \\ & Cost $\begin{array}{l}\text { unclear, Forest Pharmaceuticals has announced discontinuation of Namenda } \\ \text { on August 15, 2014 in anticipation of Namenda extended release formulation. } \\ \text { Namenda loses patent protection on April 11, 2015. }\end{array} \\ &$\hline\end{aligned}

\section{Pharmacologic treatment of behavioral symptoms}

- $\quad$ FTD spectrum disorders often present with difficult behavioral dysfunction. These can range from disinhibition, apathy, confusion, agitation to hyperorality, delusions, and uncommon hallucinations.

- $\quad$ It is important to recognize and rule out potential triggers for behavioral disturbances such as infections, electrolyte disturbances, and other medical, social stressors prior to initiating long term psychotropic medications.

\section{Selective serotonin reuptake inhibitors and similar medications}

- $\quad$ Selective serotonin reuptake inhibitors (SSRI) are attractive agents for use in FTD patients as they have historically been successful in treating clinical symptoms in psychiatric patients that resemble some of the problematic FTD behaviors. Moreover, there is evidence of serotonergic neuronal loss in autopsy specimens from FTD patients. Experience with a variety of SSRIs has been described in small, open-label trials or case series suggesting potential benefits of SSRI in managing behavioral symptoms of FTD.

- $\quad$ Citalopram has been studied in a 6-week, open-label series without placebo involving 15 FTD patients, resulting in improved disinhibition, irritability, and depressive symptoms [Class III] [25]. 
- $\quad$ Fluoxetine was described in a 3-month, open-label series of five FTD patients to improve disinhibition, compulsive, and depressive symptoms [Class IV] [26].

- $\quad$ Sertraline has been studied in several series involving both FTD and svPPA patients, as well as a case report of an FTD patient with motor neuron disease. All report improvements in behavioral symptoms [Class IV] [26-29].

- $\quad$ As is often the case, efficacy in small preliminary studies does not withstand the rigors of a randomized, placebo-controlled, clinical trial. Paroxetine showed significant behavioral improvements in a case series and open label trial [Class IV] [30] [Class III] [31], but failed to demonstrate improvements in a subsequent 6-week, double-blind, placebo-controlled, cross-over trial [Class II] [32].

- In a small randomized, double-blind, placebo-controlled trial, trazodone demonstrated improvements in irritability, agitation, and depressive symptoms 12 weeks after treatment [Class II] [33].

- It is generally believed that anti-depressants may help to manage various behavioral symptoms in FTD patients, but with most evidence coming from open-label trials or case series, the evidence to support this opinion is mainly anecdotal. In general, treatment of FTD patients with SSRIs will involve using the lowest effective dose with tolerable side effect profile to the patient, and monitoring for $4-6$ weeks on each dose for symptomatic improvement. The more commonly encountered antidepressants in our experience with FTD patients are described below.

\footnotetext{
Standard dosage $10 \mathrm{mg}$ daily to $40 \mathrm{mg}$ daily

Contraindications concomitant use with a monoamine oxidase inhibitor (MAOi), IV methylene blue, linezolid may lead to increased risk of serotonin syndrome

Main drug interactions other medications that may prolong QTc interval, primarily metabolized by CYP2C19, 2D6, and 3A4. Weak inhibitor of 2D6.

Main side effects diaphoresis, nausea, xerostomia, dizziness, headache, insomnia, somnolence, tremor, prolonged QTc interval, rare worsening depression

Special points special consideration should be placed on risk of QTc prolongation, especially on $40 \mathrm{mg}$ daily dose, strong caution against doses exceeding $20 \mathrm{mg}$ in the elderly

Cost inexpensive

Standard dosage $5 \mathrm{mg}$ daily to $20 \mathrm{mg}$ daily

Contraindications concomitant use with a monoamine oxidase inhibitor (MAOi), IV methylene blue, linezolid may lead to increased risk of serotonin syndrome

Main drug interactions metabolized by CYP2C19, 3A4

Main side effects diaphoresis, diarrhea, nausea, headache, insomnia, somnolence

Special points relatively selective SSRI and fewer drug interactions than others

Cost relatively more expensive compared to other oral medications

Standard dosage $25 \mathrm{mg}$ daily to $200 \mathrm{mg}$ daily

Contraindications concomitant use of disulfiram, concomitant use with a monoamine oxidase inhibitor (MAOi), IV methylene blue, linezolid may lead to increased risk of serotonin syndrome
} 


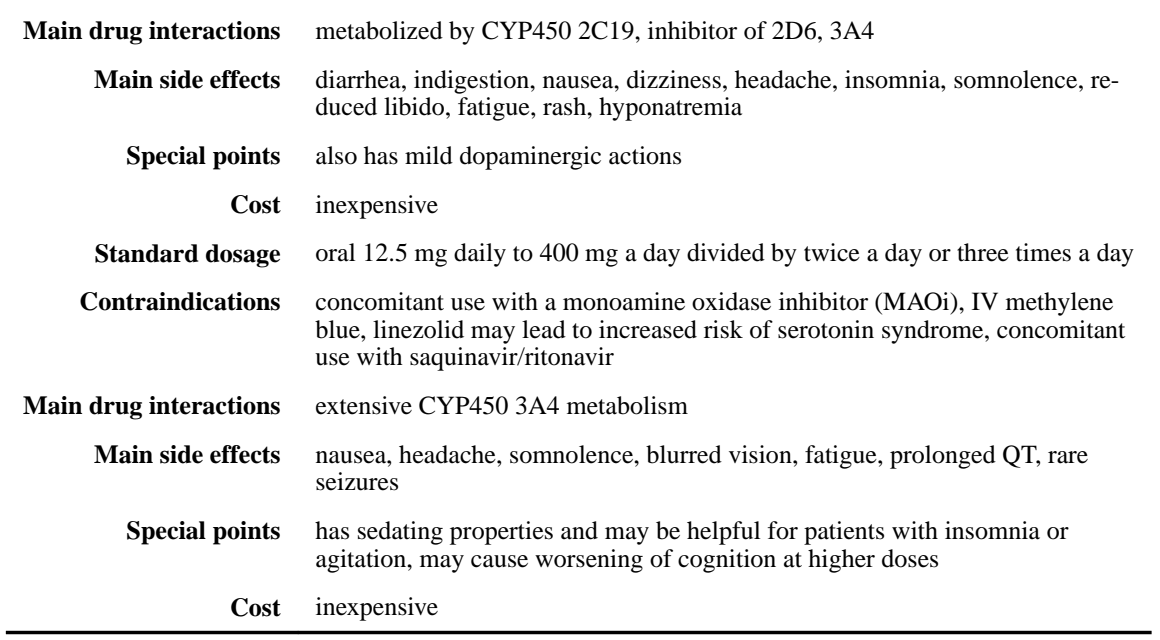

\section{Antipsychotics}

- $\quad$ Evidence for the use of antipsychotics in FTD patients is mainly from case reports and series. Risperidone and aripiprazole have been observed in small case reports to mitigate behavioral disturbances [Class IV] [30, 34-36].

- $\quad$ A24-month, open-label trial involving five groups of patients with various diagnoses of dementia were given olanzapine. Seventeen FTD patients showed improvements in delusions, NPI scores, and caregiver stress were observed [Class III] [37].

- Quetiapine was observed in a case series to demonstrate improvements in agitation in three FTD patients [Class IV] [30]. No differences in NPI was shown between baseline and quetiapine treatment in a separate double-blind, cross-over study with dextroamphetamine and quetiapine involving eight FTD patients with behavioral symptoms [Class III] [38].

- Currently, the evidence for use of antipsychotic use in FTD is limited, and all carry the risk of extrapyramidal side effects, to which FTD patients are particularly vulnerable [39]. There is now a black-box warning for all antipsychotics as the FDA determined the use of atypical antipsychotics for dementia-related behavioral symptoms to be associated with higher mortality than placebo, related to heart or infection events.

- In FTD patients with severe behavioral disturbances who invariably require an antipsychotic, 2nd or 3rd generation antipsychotics with less extrapyramidal side effects are preferred. As quetiapine has a more favorable side effect profile, especially in movement disorder patients, it may be an appropriate initial therapy [Class I] [40•]. The increased mortality and side effects with antipsychotics must ultimately be weighed against the potential benefits to quality of life an antipsychotic may provide. As caring for FTD patients is known to be extremely burdensome, the potential benefits may be largest for caregivers of patients with violent or disruptive behaviors [41]. 


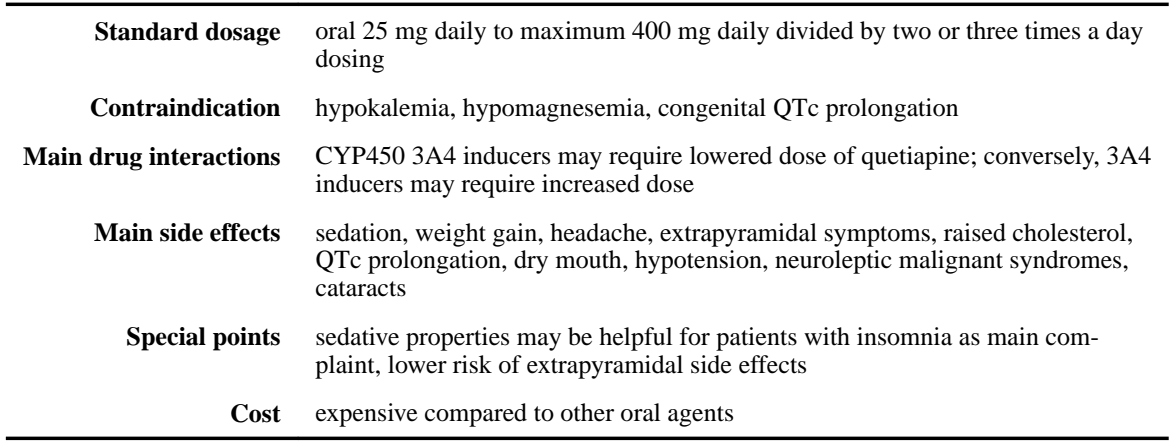

\section{Dopaminergic therapies}

- While anti-psychotic treatments rely on dopamine blockade, imaging, cerebrospinal fluid, and autopsy evidence have suggested that there is dopaminergic system dysfunction in FTD [42]. Thus, leading to use of medications that augment the dopaminergic system.

- In a small, randomized, double-blind, cross-over study using dextroamphetamine along with quetiapine with eight FTD patients, the dextroamphetamine group showed improved behavior via NPI, especially in apathy and disinhibition compared to baseline, but not with the quetiapine group [Class III] [38].

- $\quad$ Another double-blind, placebo-controlled, cross-over study using a single dose methylphenidate, a dopamine and norepinephrine reuptake inhibitor, in eight FTD patients demonstrated improvements in risk-taking behavior on a laboratory measurement of decision making, but without effects on cognition [Class III] [43].

- In summary, while dopamine modulating therapeutics have shown potentially promising preliminary results in FTD, larger placebo-controlled studies with long-term follow-up should be performed to determine their true safety and efficacy. Safety is a particular concern for these drugs in light of their potential adverse effects such as increased behavioral disturbances, risk-taking behavior, and hallucinations, symptoms that have been observed in patients receiving dopamine replacement therapy for Parkinson's disease. Routine use of stimulants in FTD is not currently recommended.

\footnotetext{
Standard dosage $20 \mathrm{mg} /$ day dose used in study

Contraindication agitated state, advanced arteriorsclerosis, symptomatic cardiovascular disease, history of drug dependency, glaucoma, moderate to severe hypertension, hyperthyroidism

Main drug interactions concomitant use with MAOI may result in hypertensive crisis

Main side effects tachycardia, myocardial infarction, Raynaud's, peripheral vascular disease, cerebrovascular accident, intracranial hemorrhage, lowered seizure threshold, aggressive behavior, psychotic disorder, drug dependence
} 


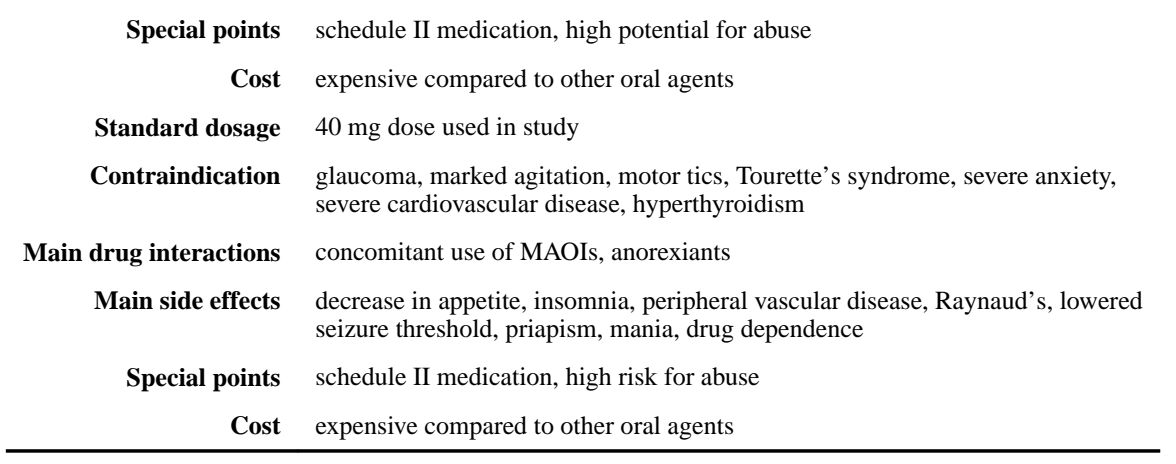

\section{Anti-epileptic agents}

- Anti-epileptic agents have been used as mood stabilizers for manic behaviors, but none have been studied rigorously in the treatment of FTD.

- $\quad$ Anti-epileptics with mood-stabilizing effects such as carbamazepine and valproic acid were reported to improve behavioral symptoms [Class IV] [30, 44]. However, chronic valproic acid use has also been studied in Alzheimer's population and showed increased brain atrophy [45].

- Topiramate is an anti-epileptic with a migraine treatment indication, moodstabilizing effects, and also a propensity to cause anorexia. Interestingly, in several case reports it has been shown to reduce hyper-orality in FTD patients [Class IV] [46-49].

- $\quad$ Overall, there is lack of quality evidence to recommend routine use of antiepileptic agents for mood stabilization. This class of medication has significant side effects that must be weighed against its potential benefits to patient and caregiver quality of life.

\footnotetext{
Standard dosage oral $200 \mathrm{mg}$ to $800 \mathrm{mg}$ twice to three times daily

Contraindications concomitant MAOi use, concomitant use of nonnucleoside reverse transcriptase inhibitors, hypersensitivity to tricyclic antidepressants (TCA), bone marrow depression; avoid abrupt withdrawal

Main drug interactions medications associated with CYP1A2, 2B6, 2C, 3A4 pathways as carbamazepine is an inducer.

Main side effects rash, myelosuppresion, hepatitis, hyponatremia, syndrome of inappropriate antidiuretic hormone secretion (SIADH), pancreatitis, congenital malformations, seizures, dizziness, drowsiness, blurred vision, impaired coordination

Special points carbamazepine is a significant inducer of its own metabolism and serum levels may decrease after chronic use

Cost inexpensive

Standard dosage $25 \mathrm{mg}$ to $200 \mathrm{mg}$ daily or twice daily

Contraindications avoid abrupt withdrawal

Main drug interactions carbonic anhydrase inhibitors, oral contraceptives

Main side effects metabolic acidosis, nephrolithiasis, osteoporosis, hypokalemia, rash, glaucoma, paresthesias, weight loss, somnolence, cognitive dysfunction

Special points topiramate has significant cognitive dysfunction side effects, regular ophthal-
} 
mological exam for glaucoma recommended

Cost expensive compared to other oral agents

\section{Oxytocin}

- $\quad$ The neuropeptide oxytocin is not only delivered to the pituitary gland, but also to regions of the CNS including the amygdala, nucleus accumbens, and prefrontal cortex where it is thought to play a role in regulating social behavior. A randomized, double-blind, placebo-controlled study examined the effects of a single dose of $24 \mathrm{IU}$ intranasal oxytocin in 20 bvFTD patients. The study demonstrated improvements in NPI via small reductions across multiple items and reduced identification of negative facial expressions, a possible sign of improved cooperative behavior. There was a trend towards improvement in a caregiver burden scale. Further trials with repeated dosing, more patients, and longer follow-up will be needed to validate efficacy of this novel use of oxytocin to treat the symptoms of bvFTD [50].

\section{Pharmacologic treatment of motor symptoms}

- $\quad$ The relationship between motor neuron disease (amyotrophic lateral sclerosis; ALS) and FTD is increasingly recognized with up to $15 \%$ of FTD patients displaying signs of motor neuron disease [51]. In 2011, a hexanucleotide repeat expansion in a 5' non-coding region of the C9ORF72 gene was found to be responsible for a large percentage of familial FTD-ALS syndromes [52-54]. Riluzole is currently the only FDA approved disease modifying treatment for ALS after two landmark trials $[55,56]$. Patients with motor neuron disease require multidisciplinary care which is beyond the scope of this article. Patients with motor neuron disease should be referred to neuromuscular specialist and/or ALS centers for care and possibility of enrolling in therapeutic clinical trials.

- A substantial portion of FTD patients also present with parkinsonism. Frontotemporal dementia and parkinsonism linked to chromosome 17 (FTDP-17) refers to autosomal dominantly inherited FTD frequently associated with parkinsonism, generally due to mutations in the tau (MAPT) or progranulin $(G R N)$ genes. Moreover, the FTD-related disorders such progressive supranuclear palsy (PSP) and corticobasal degeneration (CBD) are defined by atypical parkinsonism, typically with substantial rigidity, but infrequent tremor or levodopa response. Parkinsonism in FTD typically does not respond dopamine replacement such as levodopa/ carbidopa, but a few cases of possible benefit have been reported [Class IV] [30].

- Dopamine replacement therapy studies in PSP were also small, open-label case series that suggested patients were minimally responsive to levodopa.

However, without placebo control it is difficult to ascertain whether these are true benefits [Class IV] [57-59]. 
Although there is little evidence, in the setting of significant FTD-related parkinsonism affecting quality of life, dopamine replacement therapy can be attempted. Side effects such as nausea, hypotension, and psychosis are major inhibitors that often limit the ability to escalate dose. Dopamine agonists have not been well studied in this population, and as they can cause hallucinations, repetitive behaviors, and poor impulse control, use in FTD should be avoided.

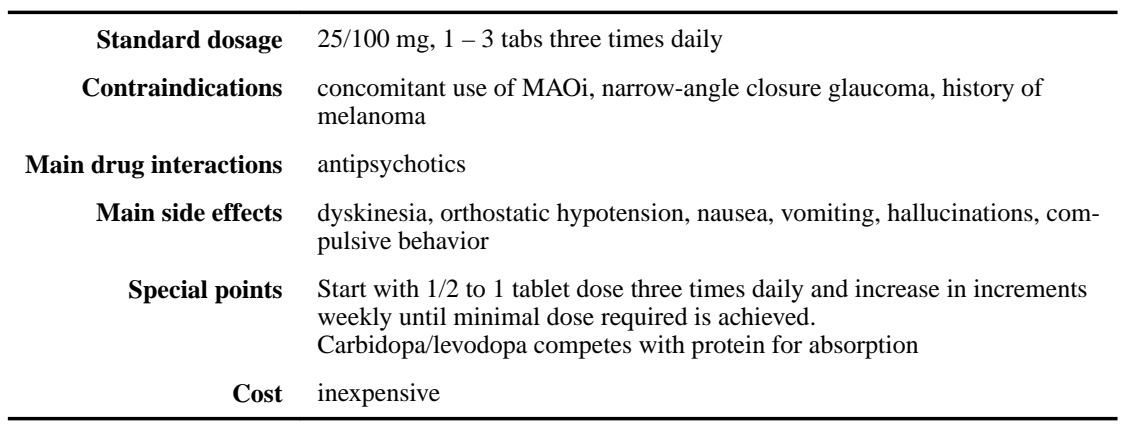

\section{Physical, occupational, and speech/swallow therapy}

- $\quad$ Physical therapy for gait and balance training will help prevent falls and increased mortality. Gait aids may be required.

- Home safety evaluation by occupational therapist for fall prevention and can provide aid for activities of daily living for patients with impaired fine motor manipulation or apraxia.

- $\quad$ Speech therapy by a therapist experienced in neurodegenerative aphasias are especially helpful in patients with primary progressive aphasias, but other FTD spectrum disorder patients may also develop dysarthria, apraxia, hypophonia that can benefit from speech therapy [60•].

- Swallow evaluation will be crucial as physicians monitor for signs of dysphagia.

\section{Emerging therapies}

- $\quad$ Recent remarkable advancements in the understanding of FTLD pathophysiology, genetics and neuropathology have led to development of potentially disease modifying treatments. Tau pathology and TDP-43 proteinopathy account for a large fraction of FTLD neuropathology. Research in tau-related therapeutics has led to several exciting treatment strategies and clinical trials. Therapeutic strategies with tau fall under four general categories: inhibition of aggregation, inhibition of phosphorylation, reduction of tau levels, and microtubule stabilization.

- $\quad$ There is now a number of clinical trials with agents that might normalize progranulin levels including nimodipine and histone deacetylase inhibitors (HDACi) [61, 62]. 
- $\quad$ Methylene blue derivatives, in particular leucomethylthioninium with a suitable counterion (LMTX), a reduced version of methylthioninium, is an inhibitor of tau aggregation and is now being investigated in a phase III clinical trial for bvFTD [63].

- Unfortunately, trials aimed at inhibition of tau phosphorylation have recently failed with lithium and tideglusib. Of note, treatment-related differences in brain atrophy were observed in the tideglusib trial $[64,65]$.

- $\quad$ Exciting animal models have demonstrated the efficacy of passive immunization directed at altered conformations of tau protein, in clearing tau pathology [66].

- $\quad$ Although a large PSP trial using davunetide, a growth factor activity-dependent neurotrophic protein-derived peptide thought to stabilize microtubules, failed to demonstrate efficacy [67••], new microtubule stabilizing agents continue to be explored as possible treatments [68].

- A number of strategies to block the expression of C9ORF72 hexanucleotide repeat expansions including antisense oligonucleotides and other small molecules seem particularly promising for this most common genetic cause of FTD $[69,70]$.

\section{Acknowledgments}

Adam L. Boxer reports grants from NIH during preparation of this paper. He also reports research support from BMS, Forum, Cortice, Genentech, TauRx, and Eli Lilly, and personal fees from Ipierian, Asceneuron, and Isis, outside the submitted work.

\section{References and Recommended Reading}

References and Recommended Reading

Papers of particular interest, published recently, have been highlighted as:

- Of importance

•• Of major importance

1. Seltman R, Matthews B. Frontotemporal lobar degeneration: epidemiology, pathology, diagnosis and management. CNS Drugs. 2012; 26:841-870. [PubMed: 22950490] Excellent review article of FTLD syndromes.

2. Rascovsky K, Hodges JR, Knopman D, et al. Sensitivity of revised diagnostic criteria for the behavioral variant of frontotemporal dementia. Brain. 2011; 134:2456-2477. [PubMed: 21810890]

3. Gorno-Tempini ML, HIllis A, Weintraub S, et al. Classification of primary progressive aphasia and its variants. Neurology. 2011; 76:1006-1014. [PubMed: 21325651]

4. Armstrong M, Litvan I, Lang A, et al. Criteria for the diagnosis of corticobasal degeneration. Neurology. 2013; 80:496-503. [PubMed: 23359374]

5. Litvan I, Agid Y, Calne D, et al. Clinical research criteria for the diagnosis of progressive supranuclear palsy (Steele-Richardson-Olszeweski syndrome): report of the NINDS-SPSP international workshop. Neurology. 1996; 47:1-9. [PubMed: 8710059]

6. Dickson DW, Ahmed Z, Algom AA, et al. Neuropathology of variants of progressive supranuclear palsy. Curr Opin Neurol. 2010; 23:394-400. [PubMed: 20610990] 
7. Brooks B, Miller R, Swash M, et al. El Escorial revisited: revised criteria for the diagnosis of amyotrophic lateral sclerosis. Amyotroph Lateral Scler Other Motor Neuron Disord. 2000; 1:293299. [PubMed: 11464847]

8. Ringholz G, Appel S, Bradshaw M, et al. Prevalence and patterns of cognitive impairment in sporadic ALS. Neurology. 2005; 65:586. [PubMed: 16116120]

9. Mackenzie IR, Neumann M, Bigio EH, et al. Nomenclature and nosology for neuropathologic subtypes of frontotemporal lobar degeneration: an update. Acta Neuropathol. 2010; 119:1-4. [PubMed: 19924424]

10. Fratiglioni L, Paillard-Borg S, Winblad B. An active and socially integrated lifestyle in late life might protect against dementia. Lancet Neurol. 2004; 3:343. [PubMed: 15157849]

11. [Accessed 23 Jul 2014] US National Institute of Health Clinical Trials Registry 2013. Available at http://clinicaltrials.gov/show/NCT00382824.

12. Moretti R, Torre P, Antonello RM, et al. Rivastigmine in frontotemporal dementia: an open-label study. Drugs Aging. 2004; 21:93107.

13. Kertesz A, Morlog D, Light M, et al. Galantamine in frontotemporal dementia and primary progressive aphasia. Dement Geriatr Cogn Disord. 2008; 25:178-185. [PubMed: 18196898]

14. Mendez MF, Shapira JS, McMurtray A, et al. Preliminary findings: behavioral worsening on donepezil in patients with frontotemporal dementia. Am J Geriatr Psychiatr. 2007; 15:84-87.

15. Kimura T, Takamatsu J. Pilot study of pharmacological treatment for frontotemporal dementia: risk of donepezil treatment for behavioral and psychological symptoms. Geriatr Gerontol Int. 2013; 13:506-507. [PubMed: 23551349]

16. Litvan I, Gomez C, Atack JR, et al. Physostigmine treatment of progressive supranuclear palsy. Ann Neurol. 1989; 26(3):404-407. [PubMed: 2802540]

17. Fabbrini G, Barbanti P, Bonifati V, et al. Donepezil in the treatment of progressive supranuclear palsy. Acta Neurol Scand. 2001; 103(2):123-125. [PubMed: 11227131]

18. Litvan I, Phipps M, Pharr VL, et al. Randomized placebo-controlled trial of donepezil in patients with progressive supranuclear palsy. Neurology. 2001; 57(3):467-473. [PubMed: 11502915]

19. Liepelt I, Gaenslen A, Godau J, et al. Rivastigmine for the treatment of dementia in patients with progressive supranuclear palsy: clinical observations as a basis for power calculations and safety analysis. Alzheimers Dement. 2010; 6(1):70-74. [PubMed: 20129321]

20. Diehl-Schmid J, Förstl H, Perneczky R, et al. A 6-month, open-label study of memantine in patients with frontotemporal dementia. Int J Geriatr Psychiatr. 2008; 23:754-759.

21. Swanberg MM. Memantine for behavioral disturbances in frontotemporal dementia: a case series. Alzheimer Dis Assoc Disord. 2007; 21:164-166. [PubMed: 17545743]

22. Boxer AL, Lipton AM, Womack K, et al. An open-label study of memantine treatment in 3 subtypes of frontotemporal lobar degeneration. Alzheimer Dis Assoc Disord. 2009; 23:211-217. [PubMed: 19812461]

23. Vercelletto $\mathrm{M}$, Boutoleau-Bretonnière $\mathrm{C}$, Volteau $\mathrm{C}$, et al. Memantine in behavioral variant frontotemporal dementia: negative results. J Alzheimer Dis. 2011; 23:749-759. First large randomized, double-blind, controlled trial of memantine in FTD patients that did not reach primary endpoints.

24. Boxer AL, Knopman DS, Kaufer DI, et al. Memantine in patients with frontotemporal lobar degeneration: a multicenter, randomized, double-blind, placebo-controlled trial. Lancet Neurol. 2013; 12:149-156. [PubMed: 23290598] Large multi-center, randomized, double-blind, controlled therapeutic trial demonstrating memantine lack of efficacy.

25. Hermann N, Black SE, Chow T, et al. Serotonergic function and treatment of behavioral and psychological symptoms of frontotemporal dementia. Am J Geriatr Psychiatr. 2012; 20:789-797.

26. Swartz JR, Miller BL, Lesser IM, et al. Frontotemporal dementia: treatment response to serotonin selective reuptake inhibitors. J Clin Psychiatry. 1997; 58:212-216. [PubMed: 9184615]

27. Mendez MF, Shapira JS, Miller BL. Stereotypical movements and frontotemporal dementia. Mov Disord. 2005; 20:742-745. [PubMed: 15786492]

28. Anneser JM, Jox RJ, Borasio GD. Inappropriate sexual behavior in a case of ALS and FTD: successful treatment with sertraline. Amyotroph Lateral Scler. 2007; 8:189-190. [PubMed: 17538783] 
29. Prodan CI, Monnon M, Ross ED. Behavioral abnormalities associated with rapid deterioration of language functions in semantic dementia respond to sertraline. J Neurol Neurosurg Psychiatry. 2009; 80:1416-1417. [PubMed: 19917830]

30. Chow TW, Mendez MF. Goals in symptomatic pharmacologic management of frontotemporal lobar degeneration. Am J Alzheimers Dis Other Demen. 2002; 17:267-272. [PubMed: 12392261]

31. Moretti R, Torre P, Antonello RM, et al. Frontotemporal dementia: paroxetine as a possible treatment of behavioral symptoms. A randomized, controlled, open 14-month study. Eur Neurol. 2003; 49:13-19. [PubMed: 12464713]

32. Deakin JB, Rahman S, Nestor PJ, et al. Paroxetine does not improve symptoms and impairs cognitive in frontotemporal dementia: a double-blind randomized controlled trial. Psychopharamcology (Berl). 2004; 172:400-408.

33. Lebert F, Stekke W, Hasenbroekx C, et al. Frontotemoporal dementia: a randomized, controlled trial with trazodone. Dement Geriatr Cogn Disord. 2004; 17:355-359. [PubMed: 15178953]

34. Curtis RC, Resch DS. Case of pick's central lobar atrophy with apparent stabilization of cognitive decline after treatment with risperidone. J Clin Psychopharmacol. 2000; 20:384-385. [PubMed: 10831030]

35. Fellgiebel A, Müller MJ, Hiemke C, et al. Clinical improvement in a case of frontotemporal dementia under aripiprazole treatment corresponds to partial recovery of disturbed frontal glucose metabolism. World J Biol Psychiatry. 2007; 8:123-126. [PubMed: 17455105]

36. Reeves RR, Perry CL. Aripiprazole for sexually inappropriate vocalizations in frontotemporal dementia. J Clin Psychopharmacol. 2013; 33:145-146. [PubMed: 23288244]

37. Moretti R, Torre P, Antonello RM, et al. Olanzapine as a treatment of neuropsychiatric disorders of Alzheimer's disease and other dementias: a 24-month follow-up of 68 patients. Am J Alzheimers Dis Other Demen. 2003; 18:205-214. [PubMed: 12955785]

38. Huey ED, Garcia C, Wassermann EM, et al. Stimulant treatment of frontotemporal dementia in 8 patients. J Clin Psychiatry. 2008; 69:1981-1982. [PubMed: 19203481]

39. Pijnenburg YA, Sampson EL, Harvey RJ, et al. Vulnerability to neuroleptic side effects in frontotemporal lobar degeneration. Int J Geriatr Psychiatr. 2003; 18:67-72.

40. Asmal L, Flegar SJ, Wang J, et al. Quetiapine versus other atypical antipsychotics for schizophrenia. Cochrane Database Syst Rev. 2013; 11:CD006625. [PubMed: 24249315] MetaAnalysis of side effect and efficacy profile of many antipsychotics.

41. Mioshi E, Foxe D, Leslie F, et al. The impact of dementia severity on caregiver burden in frontotemporal dementia and Alzheimer disease. Alzheimer Dis Assoc Disord. 2013; 27:68-73. [PubMed: 22314247]

42. Huey ED, Putnam KT, Grafman J. A systematic review of neurotransmitter deficits and treatments in frontotemporal dementia. Neurology. 2006; 66:17-22. [PubMed: 16401839]

43. Rahman S, Robbins TW, Hodges JR, et al. Methylphenidate ('Ritalin') can ameliorate abnormal risk-taking behavior in the frontal variant of frontotemporal dementia. Neuropsychopharmacology. 2006; 31:651-658. [PubMed: 16160709]

44. Poetter CE, Stewart JT. Treatment of indiscriminate, inappropriate sexual behavior in frontotemporal dementia with carbamazepine. J Clin Psychopharmacol. 2012; 31:137-138. [PubMed: 22217950]

45. Fleisher A, Truran D, Mai J, et al. Chronic divalproex sodium use and brain atrophy in Alzheimer disease. Neurology. 2011; 77:1263-1271. [PubMed: 21917762]

46. Cruz M, Marinho V, Fontenelle LF, et al. Topiramate maymodulate alcohol abuse but not other compulsive behaviors in frontotemporal dementia: case report. Cogn Behav Neurol. 2008; 21:104106. [PubMed: 18541987]

47. Nestor PJ. Reversal of abnormal eating and drinking behavior in a frontotemporal lobar degeneration patient using low-dose topiramate. J Neurol Neurosurg Psychiatry. 2012; 83:349350. [PubMed: 21507895]

48. Singam C, Walterfang M, Mocellin R, et al. Topiramate for abnormal eating behavior in frontotemporal dementia. Behav Neurol. 2013; 27:285-286. [PubMed: 23548883] 
49. Shinagawa S, Tsuno N, Nakayama K. Managing abnormal eating behaviors in frontotemporal lobar degeneration in patients with topiramate. Psychogeriatrics. 2013; 13:58-61. [PubMed: 23551414]

50. Jesso S, Morlog D, Ross S, et al. The effects of oxytocin on social cognition and behavior in frontotemporal dementia. Brain. 2011; 134:2493-2501. [PubMed: 21859765]

51. Sha SJ, Boxer A. Treatment implications of C9ORF72. Alzheiemers Res Ther. 2012; 4:46.

52. Boxer AL, Mackenzie IR, Boeve BF, et al. Clinical, neuroimaging and neuropatholgoical featuers of a new chromosome 9p-linked FTD-ALS family. J Neurol Neurosurg Psychiatry. 2011; 82:196203. [PubMed: 20562461]

53. DeJesus-Hernandez M, Mackenzie IR, et al. Expanded GGGC CC hexanucleotide repeat in noncoding region of C9ORF72 causes chromosome 9p-linked FTD and ALS. Neuron. 2011; 72:245-256. [PubMed: 21944778]

54. Renton AE, Majounie E, Waite A, et al. A hexanucleotide repeat expansion in C9ORF72 is the cause of chromosome 9p21-linked ALS-FTD. Neuron. 2011; 72:257-268. [PubMed: 21944779]

55. Bensimon G, Lacomblez L, Meininger V. A controlled trial of riluzole in amyotrophic lateral sclerosis. ALS/Riluzole Study Group. N Engl J Med. 1994; 330:585-591. [PubMed: 8302340]

56. Lacomblez L, Bensimon G, Leigh PN, et al. Dose-ranging study of riluzole in amyotrophic lateral sclerosis. Amyotrophic Lateral Sclerosis/Riluzole Study Group II. Lancet. 1996; 347:1425-1431. [PubMed: 8676624]

57. Klawans HL Jr, Ringel SP. Observations on the efficacy of L-dopa in progressive supranuclear palsy. Eur Neurol. 1971; 5(2):115-129. [PubMed: 5117103]

58. Kompoliti K, Goetz CG, Litvan I, et al. Pharmacological therapy in progressive supranuclear palsy. Arch Neurol. 1998; 55(8):1099-1102. [PubMed: 9708960]

59. Birdi S, Rajput AH, Fenton M, et al. Progressive supranuclear palsy diagnosis and confounding features: report on 16 autopsied cases. Mov Disord. 2002; 17(6):1255-1264. [PubMed: 12465065]

60. Kortte K, Rogalski E. Behavioural interventions for enhancing life participation in behavioral variant frontotemporal dementia and primary progressive aphasia. Int Rev Psychiatr. 2013; 25:237-245. Review of non-pharmacological interventions for FTD patients.

61. [Accessed 22 Aug 2014] US National Institute of Health Clinical Trials Registry 2013. Available at http://clinicaltrials.gov/show/NCT01835665.

62. [Accessed 22 Aug 2014] US National Institute of Health Clinical Trials Registry 2013. Available at http://www.clinicaltrials.gov/ct2/show/NCT02149160.

63. [Accessed 23 Jul 2014] US National Institute of Health Clinical Trials Registry 2013. Available at http://clinicaltrials.gov/ct2/show/NCT01626378.

64. Höglinger GU, Huppertz HJ, Wagenpfeil S. TAUROS MRI Investigators, et al. Tideglusib reduces progression of brain atrophy in progressive supranuclear palsy in a randomized trial. Mov Disord. 2014; 29(4):479-487. [PubMed: 24488721]

65. Tolosa E, Litvan I, Höglinger GU. TAUROS Investigators, et al. A phase 2 trial of the GSK-3 inhibitor tideglusib in progressive supranuclear palsy. Mov Disord. 2014; 29(4):470-478.

[PubMed: 24532007]

66. Yanamandra K, Kfoury N, Jiang H, et al. Anti-tau antibodies that block tau aggregate seeding in vitro markedly decrease pathology and improve cognition in vivo. Neuron. 2013; 80(2):402-414. [PubMed: 24075978]

67. Boxer A, Lang A, Grossman M. AL-108-231 investigators. Davunetide in patients with progressive supranuclear palsy: a randomized, double-blind, placebo-controlled phase 2/3 trial. Lancet Neurol. 2014; 13:676-685. [PubMed: 24873720] Largest clinical trial of PSP to date.

68. [Accessed 23 Jul 2014] US National Institute of Health Clinical Trials Registry 2013. Available at http://clinicaltrials.gov/ct2/show/NCT02133846.

69. Donnelly CJ, Zhang PW, Pham JT, et al. RNA toxicity from the ALS/FTD C9ORF72 expansion ismitigated by antisense intervention. Neuron. 2013; 80:415-428. [PubMed: 24139042]

70. Su Z, Zhang Y, Gendron TF, et al. Discovery of a biomarker and lead small molecules to target r(GGGGCC)-associated defects in c9FTD/ALS. Neuron. 2014 